\title{
New insights into the hydrogen peroxide reduction reaction and its comparison with the oxygen reduction reaction in alkaline media on well-defined platinum surfaces
}

\author{
Rubén Rizo, Juan M. Feliu, Enrique Herrero* \\ Instituto de Electroquímica, Universidad de Alicante, Apdo. 99, E-03080 Alicante, Spain
}

\section{A R T I C L E I N F O}

\section{Article history:}

Received 1 February 2021

Revised 29 March 2021

Accepted 16 April 2021

Available online 28 April 2021

\section{Keywords:}

Platinum electrodes

Oxygen reduction reaction

Hydrogen peroxide reduction reaction

Single crystal surfaces

Effect of the surface structure

\begin{abstract}
A B S T R A C T
The hydrogen peroxide reduction reaction (HPRR) is investigated at $\mathrm{pH}=13$ on the Pt basal planes and stepped surfaces with (111) terraces separated by either monatomic (100) or (110) steps. A quantitative analysis of the surface structure effect revealed that $\mathrm{Pt}(111)$ is the most active surface and its activity progressively decreases when steps are introduced. Additionally, inhibition of the HPRR is observed at low potentials, which onset potential is governed by the $\mathrm{OH}_{\mathrm{ads}}$ and the point of maximum entropy (pme) of the interphase. Experiments with different rotation rates suggest the formation of an HPRR intermediate linked to the inhibition process, which is more strongly adsorbed on (110) than (100) steps. Finally, a comparison of the HPRR and ORR (oxygen reduction reaction) illustrated the important differences for both reactions, which are dependent on the step density. These divergences have been discussed based on adsorbed intermediates and $\mathrm{O}_{2}$ interactions with the Pt surface.
\end{abstract}

(c) 2021 Elsevier Inc. All rights reserved.

\section{Introduction}

The oxygen reduction reaction (ORR) is of paramount importance in electrocatalysis since it takes part in several practical devices, such as metal-air batteries and fuel cells. It is also the most suitable counter electrode reaction in oxidation processes. The complete reduction of oxygen to water involves the exchange of 4 electrons according to Eq. (1):

$\mathrm{O}_{2}+4 \mathrm{H}^{+}+4 \mathrm{e}^{-} \rightleftharpoons 2 \mathrm{H}_{2} \mathrm{O} \quad E^{o}=1.229 \mathrm{~V}$

In alkaline solutions, the equation is transformed into:

$\mathrm{O}_{2}+2 \mathrm{H}_{2} \mathrm{O}+4 \mathrm{e}^{-} \rightleftharpoons 4 \mathrm{OH}^{-}$

This complex reaction involves the transfer of four electrons and protons and the cleavage of the $\mathrm{O}-\mathrm{O}$ double bond to form $40-\mathrm{H}$ bonds. The presence of multiple steps implies the participation of several reaction intermediates, whose importance in the mechanism may change as a function of solution $\mathrm{pH}$. Moreover, during the reduction process, the ORR can proceed through a two-electron step to form hydrogen peroxide as an intermediate, which can further be reduced to water with the consequent

\footnotetext{
* Corresponding author.

E-mail address: herero@ua.es (E. Herrero).
}

transfer of two additional electrons, or as the final product [1] when its reduction is kinetically inhibited. It should be highlighted that hydrogen peroxide is thermodynamically unstable because it can undergo oxidation and reduction processes according to:

$\mathrm{O}_{2}+2 \mathrm{H}^{+}+2 \mathrm{e}^{-} \rightleftharpoons \mathrm{H}_{2} \mathrm{O}_{2} \quad E^{o}=0.682 \mathrm{~V}$

$\mathrm{H}_{2} \mathrm{O}_{2}+2 \mathrm{H}^{+}+2 \mathrm{e}^{-} \rightleftharpoons 2 \mathrm{H}_{2} \mathrm{O} \quad E^{o}=1.776 \mathrm{~V}$

In alkaline media, hydrogen peroxide deprotonates $\left(\mathrm{pK}_{\mathrm{a}}=11.65\right)$ and reactions (3) and (4)transform into:

$\mathrm{O}_{2}+\mathrm{H}_{2} \mathrm{O}+2 \mathrm{e}^{-} \rightleftharpoons \mathrm{HO}_{2}^{-}+\mathrm{OH}^{-}$

$\mathrm{HO}_{2}^{-}+\mathrm{H}_{2} \mathrm{O}+2 \mathrm{e}^{-} \rightleftharpoons 3 \mathrm{OH}^{-}$

Since the standard oxidation potential of hydrogen peroxide (rection (3)) is lower than that of the reduction reaction (reaction (4)), the dismutation of hydrogen peroxide to produce water and oxygen is a spontaneous process. However, these reactions are kinetically slow and for this reason, hydrogen peroxide is kinetically stable in the absence of an appropriate catalyst. Thus, the detection of hydrogen peroxide during the ORR implies that the reduction of hydrogen peroxide is inhibited.

Pt has been considered as the best catalyst among pure metals for ORR exhibiting the highest number of transferred electrons per $\mathrm{O}_{2}$ molecule with almost negligible formation of hydrogen 
peroxide in the whole potential range [2-4]. Nevertheless, sluggish kinetics and high overpotentials are indeed observed for $\mathrm{Pt}$ catalysts, which hinder the commercialization of fuel cells and metal-air batteries. Therefore, to improve both issues and be able to obtain commercial competitive cathodes for these devices, it is essential to carry out fundamental studies to understand the ORR mechanism, so that strategies for improving its activity can be devised.

During the last decades, many theoretical and experimental studies have proposed different ORR mechanisms [1,5-9]. Despite that, the detailed mechanism remains still unclear. The main reason for that is that the intermediates formed during the reaction are difficult to identify due to their short lifetime and low coverage. Thus, innovative, and specific strategies are essential to obtain new insights into the ORR mechanism. In this sense, recent fundamental studies, performed on well-defined Pt single crystals and polycrystalline Pt, contributed to shed light on the mechanism toward ORR. It was proposed that adsorbed $\mathrm{OOH}$ is the first one-electron transfer process to yield $\mathrm{H}_{2} \mathrm{O}$ or $\mathrm{H}_{2} \mathrm{O}_{2}$ in acid media on $\mathrm{Pt}(111)$ electrodes $[9,10]$. On the other hand, a superoxide anion radical $\left(\mathrm{O}_{2}^{-}\right)$has been postulated for the ORR after the first electron transfer in alkaline media [11-13]. Additionally, since $\mathrm{H}_{2} \mathrm{O}_{2}$ has been detected as an intermediate in the reaction, the studies of the hydrogen peroxide reduction reaction (HPRR) are also important to elucidate the mechanism of the ORR.

Furthermore, we have recently described an effect of the surface charge and the interfacial water on the ORR and HPRR, leading to mechanistic consequences for both reactions [13,14], mainly because water is either a reactant or a product in the reactions. Experiments on Pt stepped surfaces showed that the inhibition at low potentials, which is always observed for both reactions, is close to the potential of maximum entropy (pme) of terraces and steps in acid media. The value of the pme is closely related to the potential of zero free charge (pzfc) [13]. However, the study of the role of the surface sites in the HPRR in strong alkaline electrolytes $(\mathrm{pH}=13)$ and their comparison with ORR at the same $\mathrm{pH}$, need yet to be explored in detail. These effects are important to understand the influence of the solution $\mathrm{pH}$ in the reaction. In that sense, it has been observed that the reaction order for the single crystal electrodes in acidic and alkaline solutions for the ORR is completely different. Thus, in acidic solution, the electroactivity sequence is $\mathrm{Pt}(110)>\mathrm{Pt}(111)>\mathrm{Pt}(100)$ whereas, in alkaline solution, the Pt (111) is the most active of the three basal planes [7,15-17].

In this work, additional hanging meniscus rotating ring disk electrode (HMRDE) studies on Pt basal planes and stepped surfaces for HPRR in $0.1 \mathrm{M} \mathrm{NaOH}$ solutions are performed to gain new insights into the reaction mechanism in this media. A detailed comparison with ORR results is also included in order to obtain more information about the possible formed intermediates and the effect of the surface charge properties on the reaction.

\section{Experimental}

The experiments were carried out in a two-compartment electrochemical glass cell, using a Pt wire as a counterelectrode and a reversible hydrogen electrode (RHE) as a reference electrode. The platinum single crystal electrodes used as working electrodes were prepared by using the method described by Clavilier [18]. $\mathrm{Pt}(111), \mathrm{Pt}(100)$ and $\mathrm{Pt}(110)$ low index planes and stepped surfaces have been used for the studies. These stepped surfaces belong to the series $\operatorname{Pt}(S)[(n-1)(111) \times(110)]$ and $\operatorname{Pt}(S)[n(111) \times$ (100)] and contain $n$ atom-wide terraces separated by monoatomic (110) and (100) steps, and can be also termed as $\operatorname{Pt}(\mathrm{n}, \mathrm{n}$, $n-2)$ and $\operatorname{Pt}(n+1, n-1, n-1)$, respectively. For these surfaces, the step density can be calculated according to $\frac{2}{d \sqrt{3}\left(n-\frac{2}{3}\right)}$

for the $\operatorname{Pt}(\mathrm{n}, \mathrm{n}, \mathrm{n}-2)$ surfaces and

$\frac{2}{d \sqrt{3}\left(n-\frac{1}{3}\right)}$

for the $\operatorname{Pt}(\mathrm{n}+1, \mathrm{n}-1, \mathrm{n}-1)$ surfaces. In these equations, $d$ is the atomic diameter of platinum.

Before any electrochemical experiment, Pt working electrodes were always flame annealed in a propane-air flame, cooled in $\mathrm{Ar} /$ $\mathrm{H}_{2}$ (3:1) reducing atmosphere, protected with an ultrapure water drop saturated with this atmosphere, and immersed in the electrochemical cell at controlled potential [19]. STM results indicate that the surfaces obtained after this treatment correspond to the nominal surfaces structures for the $\operatorname{Pt}(111), \operatorname{Pt}(100)$, and stepped surfaces $[20,21]$. For the $\operatorname{Pt}(110)$ electrode, this treatment leads to the formation of a $(1 \times 2)$ surface structure. Although the $(1 \times 1)$ structure can be obtained when the Pt(110) electrode is cooled down in a CO containing atmosphere [22-24], this surface structure transforms into a $(1 \times 2)$ structure when the potential is above $0.8 \mathrm{~V}$. Since the study of the HPRR and the HPOR requires potentials above this limit, the $(1 \times 2)$ structure has been used for the studies because this surface structure is stable in the potential limits employed in this work.

Solutions were prepared using $\mathrm{NaOH} \cdot \mathrm{H}_{2} \mathrm{O}$ (Merck, Suprapur, $99.99 \%$ ) and $\geq 30 \% \mathrm{H}_{2} \mathrm{O}_{2}$ solution (Fluka, Trace SELECT ${ }^{\circledR}$ Ultra, for trace analysis) dissolved in ultrapure water (Elga PureLab Ultra, $18.2 \mathrm{M} \Omega \mathrm{cm}$ ) and deoxygenated using $\mathrm{Ar}$ (N50, Air Liquide). $\mathrm{H}_{2}$ (N50, Air Liquide) for the reference electrode and $\mathrm{O}_{2}$ (N50, Air Liquide) for the ORR studies were also employed.

The cyclic voltammograms were performed at room temperature by using a signal generator EG\&G PARC and eDAQ EA161 potentiostat with an eDAQ e-corder ED401 recording system. Experiments in hydrodynamic conditions were carried out in the hanging meniscus rotating disk electrode (HMRDE) configuration using an EDI101 rotating electrode.

\section{Results and discussion}

\subsection{HPRR on Pt basal planes}

The important effect of the adsorbed species on the Pt surface in electrocatalysis has been widely verified for several reactions, and especially for the ORR and HPRR [25]. Moreover, in these adsorption processes, the solution $\mathrm{pH}$ of the electrolyte can play an important role. Thus, the analysis of the voltammetric responses and the characterization of adsorbed species on the electrode surface is essential to get new insights on the electroactivity of Pt electrodes in the reactions. Fig. 1a shows the voltammetric profiles for the three basal planes employed in this study in the supporting electrolyte. It should be noted that the adsorption processes observed in the absence of $\mathrm{O}_{2}$ or $\mathrm{H}_{2} \mathrm{O}_{2}$ are still taking place in the presence of these molecules [16,26]. As can be observed, the adsorption processes taking place in the stability region of the platinum low index planes of platinum, namely the hydrogen and the $\mathrm{OH}$ adsorption/desorption processes, are strongly dependent on the Pt surface topography.

For the $\mathrm{Pt}$ (111) surface, hydrogen and $\mathrm{OH}$ adsorption processes take place in two different potential windows separated by the socalled double layer region $[7,27]$. Thus, hydrogen adsorption occurs at potentials below $0.4 \mathrm{~V}$, whereas the onset for $\mathrm{OH}$ adsorption occurs at ca. $0.6 \mathrm{~V}$ and extends to $0.9 \mathrm{~V}$. Above $1.0 \mathrm{~V}$, the adsorbed $\mathrm{OH}$ is transformed into adsorbed $\mathrm{O}$. The formation of adsorbed $\mathrm{O}$ can lead to surface disordering [28,29]. On the other hand, for Pt 

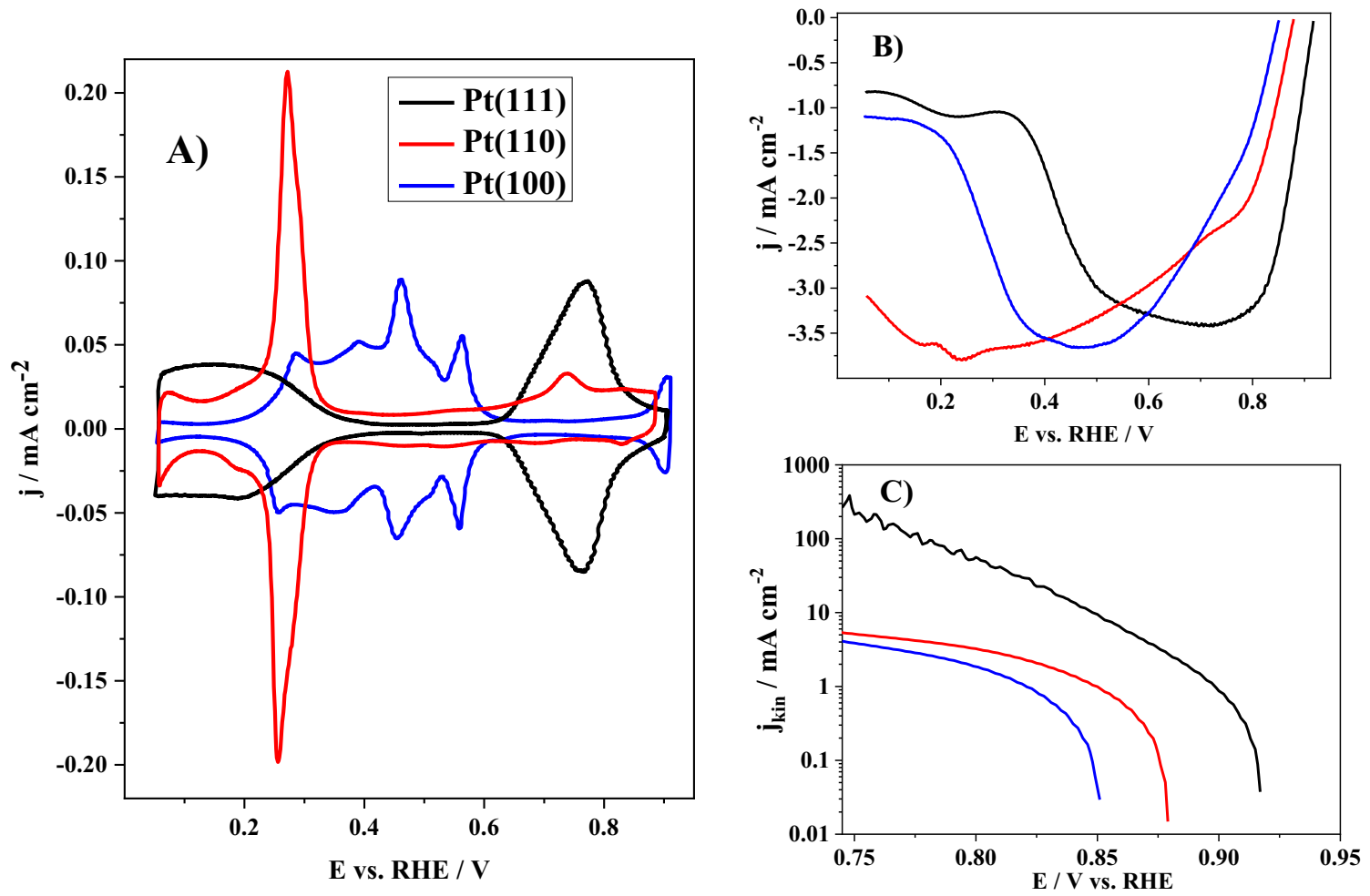

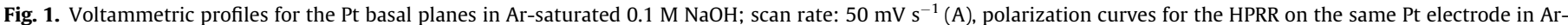
saturated $0.1 \mathrm{M} \mathrm{NaOH}$ and $2 \mathrm{mM} \mathrm{H}_{2} \mathrm{O}_{2}$; scan rate: $50 \mathrm{mV} \mathrm{s}^{-1}$, rotation rate: $2500 \mathrm{rpm}(\mathrm{B})$ and kinetic currents extracted from the HPRR polarization curves (C).

(110) and Pt(100), both processes overlap. On the Pt(100) surface, four overlapping peaks can be distinguished in the voltammetric profile at $0.28,0.39,0.46$, and $0.56 \mathrm{~V}$. The ones taking place at low potentials (i.e., those at 0.28 and $0.39 \mathrm{~V}$ ) are related to the adsorption of hydrogen whereas those at higher potentials are related to the adsorption of $\mathrm{OH}[7,30]$. The single peak observed for the $\mathrm{Pt}(110)$ electrode at $0.27 \mathrm{~V}$ corresponds to the competitive adsorption of $\mathrm{H}$ and $\mathrm{OH}$. At potentials lower than the peaks the surface is covered by adsorbed hydrogen whereas at higher potentials $\mathrm{OH}$ is the adsorbed species. For this latter surface, an additional process is observed at $0.78 \mathrm{~V}$, related to further adsorption of $\mathrm{OH}$ on this electrode.

Fig. $1 \mathrm{~b}$ shows the HPRR voltammetric profiles for the three electrodes in $0.1 \mathrm{M} \mathrm{NaOH}+2 \mathrm{mM} \mathrm{H}_{2} \mathrm{O}_{2}$. Only the negative scan direction is displayed for the sake of comparison, although the behavior of the positive scan direction mimics the one shown in the figure (see Fig. S1). The voltammetric profiles display the typical features observed for the HPRR, with a region at high potentials where the current is controlled by the ratio of the reactions rates for the HPRR and HPOR, and the diffusion of $\mathrm{H}_{2} \mathrm{O}_{2}$ to the surface[31], followed by a region at more negative values characterized by a stationary limiting current. In the case of the Pt (110) electrode, this stationary behavior is not well-defined. Furthermore, the inhibition of the HPRR can be identified at high overpotentials for the three basal planes, where the current density (in absolute value) diminishes. In this region, the current for the $\mathrm{Pt}(111)$ and $\mathrm{Pt}(100)$ electrodes reach a value close to zero, which implies that the HPRR is almost completely inhibited, whereas higher values are obtained for the Pt (110) surface.

The data on the adsorbed species on the electrodes will be used to analyze the HPRR curves in the three regions. As can be seen, the onset for the oxidation is $\operatorname{Pt}(111)>\operatorname{Pt}(110)>\operatorname{Pt}(100)$. It should be noted that $\mathrm{H}_{2} \mathrm{O}_{2}$ can suffer the oxidation and reduction processes of reactions (3) and (4). In fact, both processes, the hydrogen per- oxide oxidation reaction (HPOR) and the HPRR overlap in the region around $0.9 \mathrm{~V}$ (see for instance Fig. S1 or Fig. 3). For higher potentials, oxidation currents dominate and for lower potentials reduction currents are the main contribution. Thus, the onset for the HPRR is controlled by the balance of the two possible reactions. If the rate constant for both processes were the same, it would be expected that the onset for the HPRR (and for HPOR) was located in the mean value of the equilibrium potentials of both reactions, that is, $1.229 \mathrm{~V}$ vs. RHE. The observation of a lower potential value for the onset of the HPRR implies that the kinetics of this reaction in this region are slower than those corresponding to the HPOR.

As aforementioned, Pt (111) exhibits the highest onset potential for HPRR (above $0.90 \mathrm{~V}$ ) within the three basal planes shown in Fig. $1 \mathrm{~B}$, whereas the reaction initiates at lower values for $\mathrm{Pt}$ (110) and Pt (100), whose onset are $0.88 \mathrm{~V}$ and $0.85 \mathrm{~V}$, respectively. The reason for the different onset potential is the formation rate of adsorbed $\mathrm{OH}$. The reduction of $\mathrm{H}_{2} \mathrm{O}_{2}$, which at this $\mathrm{pH}$ is in the form of $\mathrm{HO}_{2}^{-}$, implies its adsorption which, in turn, leads to the cleavage of the $\mathrm{O}-\mathrm{O}$ bond to form adsorbed $\mathrm{OH}$ and $\mathrm{O}$. This latter species evolves immediately to adsorbed $\mathrm{OH}$, and the final step in the reaction is the release of three $\mathrm{OH}^{-}$ions to the solution and the transfer of two electrons. Thus, in this process, adsorbed $\mathrm{OH}$ is a key element in the reactivity, because it should be labile enough to adsorb and desorb with low barriers. For the Pt(111), the onset for the HPRR is very close to the onset for the $\mathrm{OH}$ desorption on the $\mathrm{Pt}(111)$ electrode, as Fig. $1 \mathrm{~A}$ shows. In fact, the $\mathrm{OH}$ adsorption/desorption process is reversible and occurs between 0.6 and $0.9 \mathrm{~V}$, implying that $\mathrm{OH}$ can be easily adsorbed/desorbed in this region. For the other two electrodes, $\operatorname{Pt}(110)$ and $\operatorname{Pt}(100)$, the onset for $\mathrm{OH}$ desorption is at lower potentials, which indicates that $\mathrm{OH}$ is strongly bonded to the surface at $0.9 \mathrm{~V}$ and its desorption is, comparatively, more difficult. In this sense, it would be expected that the onset for $\operatorname{Pt}(100)$ was lower than that of $\operatorname{Pt}(110)$ because the complete desorption of $\mathrm{OH}$ on the $\mathrm{Pt}(100)$ electrode takes place 
at higher potentials. However, the small bump observed for Pt (110) at $0.78 \mathrm{~V}$ in Fig. $1 \mathrm{~A}$, also related to adsorbed $\mathrm{OH}$, suggests some lability of the adsorbed $\mathrm{OH}$ layer in this potential region, justifying the higher potential onset with respect to $\mathrm{Pt}(100)$.

The order of activities obtained in this region, Pt (111) > Pt $(110)>P t(100)$, is the same one as that obtained for ORR in the same electrolyte planes [7,15-17]. Although the analysis of the differences and similarities between the ORR and the HPRR will be carried out later, this fact suggests that $\mathrm{OH}$ adsorption kinetics is an important element for both reactions in this potential region.

Kinetic currents, i.e., those would have been obtained in absence of diffusion limitations, can be obtained behavior using Koutecky-Levich equations [7]. It should be highlighted that Koutecky-Levich analysis is only valid when the kinetics of the process fulfill certain conditions, that is, it is a first-order reaction with respect to the reactants[32]. Fig. 1C shows the kinetic currents for the HPRR on the three Pt basal planes in the charge transfer controlled region. Two different linear Tafel regions are observed in the curves. The Tafel slopes values in the high potential region, that is, between 0.92 and $0.87 \mathrm{~V}$ for $\mathrm{Pt}(111), 0.88$ and $0.85 \mathrm{~V}$ for $\mathrm{Pt}$ (110) and 0.85 and $0.83 \mathrm{~V}$ for $\mathrm{Pt}(100)$, are close to $15 \mathrm{mV}$ for the three electrodes. These low apparent Tafel values are the consequence of the joint contribution of both HPRR and HPOR to the measured current densities in this region. In fact, the current values obtained for this region are artificial because the KouteckyLevich analysis is not strictly valid in this region. At lower potentials, when the HPRR is the only significant contribution to the total current, and the equation Koutecky-Levich can provide reliable values, the obtained Tafel slopes are $142 \mathrm{mV}, 236 \mathrm{mV}$, and $63 \mathrm{mV}$ for $\mathrm{Pt}(100), \operatorname{Pt}(110)$, and Pt (111), respectively. The analysis of the Tafel slopes when adsorbed species are involved is complicated because they contain not only information on the electrode transfer kinetics of the process but also depend on the adsorbed species isotherm. As aforementioned, adsorbed $\mathrm{OH}$ is an intermediate for HPRR/ORR and then this species may contribute to the Tafel slope. The following expression has been used to include the effect of $\mathrm{OH}$ in the Tafel slope [7]:

$m_{\text {Tafel }}=\left|\frac{1}{\frac{\partial \log \left(\theta_{O H}\right)}{\partial E}-\frac{\alpha F}{R T \ln (10)}}\right|$

This equation justifies the significantly lower value obtained for the $\mathrm{Pt}(111)$ because in this region the change in the $\mathrm{OH}$ coverage contributes significantly to the measured value [7]. On the other hand, the values for the $\operatorname{Pt}(110)$ and $\operatorname{Pt}(100)$ electrodes are very similar to those obtained for the ORR for the same potential region [7], again highlighting the similarities of the ORR and HPRR reactions in this region.

The second region that is important to discuss is the region where the HPRR is inhibited. In previous work, a correlation between the onset potential for the decay of the current at low potentials $\left(E_{\text {inhibition }}\right)$ and the electronic properties of the different platinum surfaces was found [13]. The onset for the inhibition was observed around the local potential of maximum entropy (pme). This potential marks the change in the orientation of the water molecules at the interface: at potential values more negative than the local pme the water molecules are oriented with the hydrogen atoms pointing toward the surface [33], and this configuration inhibits the HPRR. For the Pt(111) electrode in acid media, the pme is located in the region where no $\mathrm{OH}$ is adsorbed and its potential value is independent of the $\mathrm{pH}$ in the SHE scale [33]. The extrapolation of this trend to alkaline media would place the pme in the region where $\mathrm{OH}$ is adsorbed. However, the presence of adsorbed $\mathrm{OH}$ alters the water interaction at the interface [34], and the pme is located close to the onset of $\mathrm{OH}$ adsorption [33]. For the other two surfaces, since the process of $\mathrm{H}$ and $\mathrm{OH}$ adsorp- tion overlap, the pme lies in the region where the coverage of both species is similar. Thus, the inhibition of the HPRR requires potentials negative to the pme where no $\mathrm{OH}$ is adsorbed $[7,13]$. The results obtained for this $\mathrm{pH}$ agrees with this trend. $\mathrm{E}_{\text {inhibition }}$ for $\mathrm{Pt}(111), \operatorname{Pt}(100)$, and $\mathrm{Pt}(110)$ electrodes are located at 0.64, 0.4, and $0.27 \mathrm{~V}$, respectively, which correspond to the potentials where $\mathrm{OH}$ coverage becomes negligible.

\subsection{HPRR and HPOR on Pt stepped surfaces}

To further investigate the effect of the surface structure and the electronic properties on the reactions, stepped surfaces were used. The selected surfaces are those containing (111) terraces separated by monoatomic (110) or (100) steps. Because of the large dipole created on the step due to the Smoluchowski effect [35], the perturbation on the surface energy originated by the step is large enough to induce significant changes in the behavior of these surfaces. For the other two types of stepped surfaces, those containing (100) and (110) terraces, the perturbation created by the step is significantly smaller $[36,37]$ and the differences in the catalytic behavior when compared to the respective low index planes are very small $[7,38,39]$.

The addition of steps on the (111) surface results in the appearance of new peaks in the voltammetric profiles of the electrodes with respect to that of the $\mathrm{Pt}(111)$ plane. As can be seen in Fig. 2, a reversible pair of peaks at $0.26 \mathrm{~V}$ for the (110) step and a less reversible one at $0.36-0.42 \mathrm{~V}$ for the (100) steps appear and grow as the step density increases in parallel with the diminution of the charge related to the hydrogen and $\mathrm{OH}$ adsorption on the (111) terraces. Moreover, the separation between both signals increases with the step density. The new peaks associated with the presence of the steps are due to the competitive adsorption of hydrogen and $\mathrm{OH}$ on the top part of the step. Thus, at potentials negative to the peak, the hydrogen is adsorbed on the step, whereas $\mathrm{OH}$ is adsorbed at more positive potentials. The local potential of maximum entropy for the step is at the peak position [33].

For the HPRR, Fig. 3 shows the negative scan directions on the two series of stepped surfaces in $0.1 \mathrm{M} \mathrm{NaOH}$ in presence of $\mathrm{H}_{2} \mathrm{O}_{2}$ under hydrodynamic conditions. The curves were recorded up to $1.2 \mathrm{~V}$ to study not only the HPRR but also the HPOR. The HPRR and HPOR take place under diffusion control at potentials below $0.8 \mathrm{~V}$ and above $1.0 \mathrm{~V}$ vs. RHE, respectively. Between these potentials, the charge transfer controlled region for both reactions is located, which overlap in the same potential range [40]. A close analysis of the effect of the surface structure in this potential region reveals that $\mathrm{Pt}(111)$ is the most active surface for the HPRR since the lowest overpotential for the HPRR is measured for this surface. The HPRR curves displace to lower potentials when (110) or (100) steps are introduced into the (111) surface, which is a clear indication that the steps are less active than the terrace sites, in consonance with the behavior previously obtained for ORR using the same surfaces and the same electrolyte [7]. Analogous conclusions can be extracted for the positive scan directions under the same conditions (Fig. S2). To quantify this effect, the half-wave potential $\left(E_{1 / 2}\right)$ is commonly used and can provide values for the overpotential for the HPRR and HPOR [40]. To calculate this parameter, the HPRR/HPOR voltammograms can be decomposed into the sum of both processes using conventional equations for S-shaped electrochemical processes (Fig. S3) [40]:

$E=E_{1 / 2}+m \log \left(\frac{j_{\mathrm{lim}}-j}{j}\right)$

being $E_{1 / 2}$, the half-wave potential, $E$, the applied potential, $j$, the current density and $j_{\text {lim, }}$ the limiting current density, and considering 


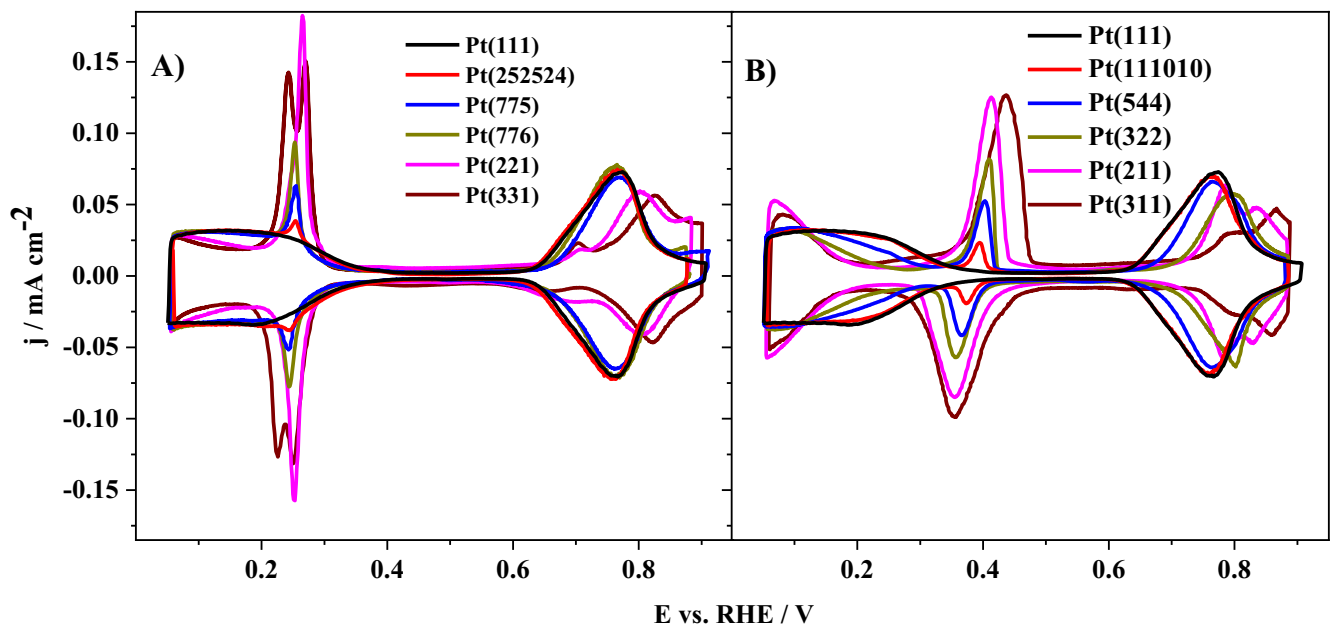

Fig. 2. Voltammetric profiles for $\mathrm{Pt}(\mathrm{S})[(\mathrm{n}-1)(111) \times(110)](\mathrm{A}) \mathrm{Pt}(\mathrm{S})[(\mathrm{n})(111) \times(100)](\mathrm{B})$ stepped surfaces in Ar-saturated $0.1 \mathrm{M}$ NaOH solution. Scan rate: $50 \mathrm{mV} \mathrm{s}^{-1}$.

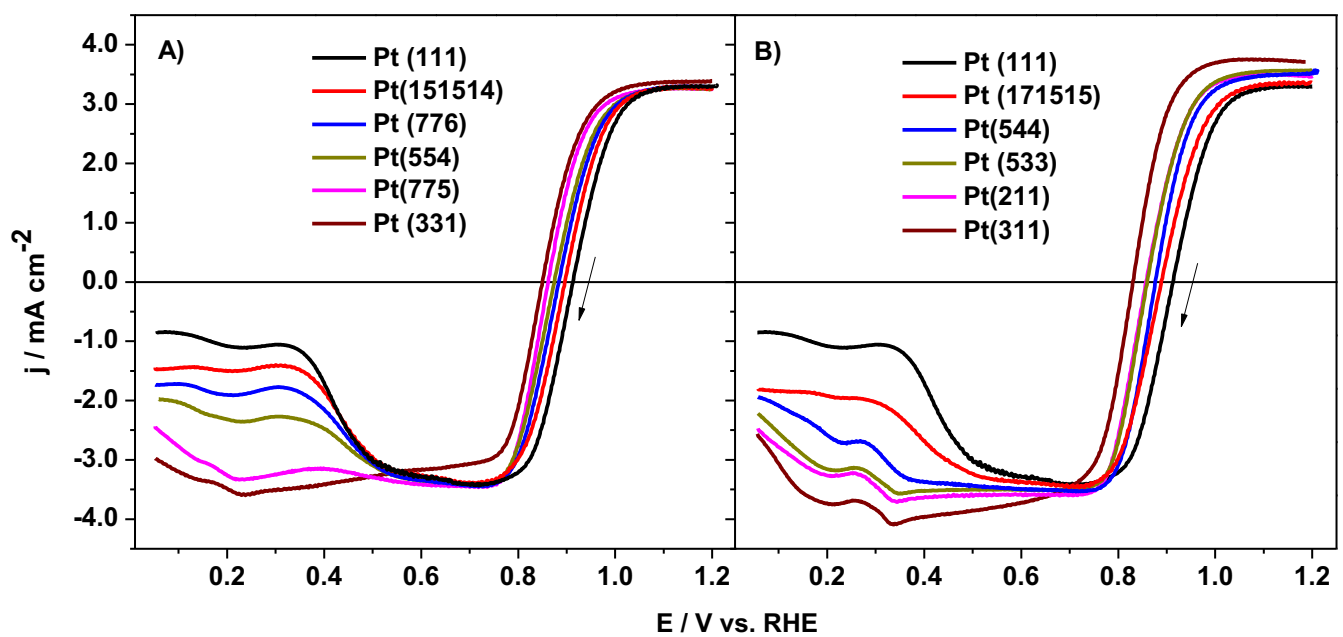

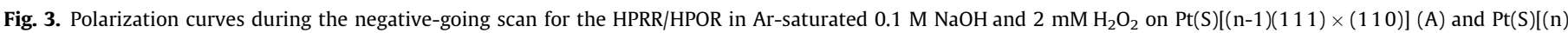
$(111) \times(100)](B)$ surfaces; scan rate: $50 \mathrm{mV} \mathrm{s}^{-1}$, rotation rate: $2500 \mathrm{rpm}$.

$\mathrm{m}=60 \mathrm{mV}$. Then, fitting the experimental curves to equation (10), the $E_{1 / 2}$ values for HPRR and HPOR for the positive and negative scan directions are calculated and plotted versus the angle of the surface with the (111) plane (Fig. 4).

As can be observed, $\mathrm{Pt}(111)$ shows the highest activity for HPRR and this activity decreases with the step density for $\mathrm{Pt}(111)$ vicinal surfaces, regardless of the direction of the scan. The activity for the basal planes follows the order $\operatorname{Pt}(111)>\operatorname{Pt}(110)>\operatorname{Pt}(100)$ for HPRR. However, the opposite behavior was found for HPOR. In this case, the Pt(111) shows the lowest activity because of the highest $E_{1 / 2}$, whereas $\operatorname{Pt}(100)$ and $\operatorname{Pt}(110)$ show higher activity. The comparison of the values obtained during the negative and positivegoing scan provides information about the influence of the oxides since Pt oxide is forming above $1 \mathrm{~V}$ (Fig. S4). As can be observed, the activities for HPRR on all the oxide-covered surfaces decrease whereas their activity toward HPOR increases. Thus, it can be proposed that the value for which the current density is zero for the HPOR/HPRR on the different surfaces should have the same properties. Probably, this value is linked with the potential at which the adsorbed $\mathrm{OH}$ is transformed into oxides.

On the other hand, the activities for HPRR follow the same ORR activity trend previously reported. However, the $E_{1 / 2}$ value is always more positive for HPRR than for ORR [7]. Thus, if $\mathrm{H}_{2} \mathrm{O}_{2}$ is an active intermediate in the ORR reaction at these potentials it will not be detected during the reaction since any $\mathrm{H}_{2} \mathrm{O}_{2}$ formed will be inmediately reduced to water. However, on oxide-covered surfaces the HPRR activity is lower and then this intermediate might be detected. In fact, the formation of $\mathrm{H}_{2} \mathrm{O}_{2}$ during the negativegoing scan in alkaline media on $\operatorname{Pt}(100)$ and $\operatorname{Pt}(110)$ has been reported $[41,42]$.

Another important element in Fig. 3 is the inhibition of the reaction at low potentials. This process diminishes with the addition of the steps. As aforementioned, this inhibition is correlated with the pme and/or the presence of adsorbed $\mathrm{OH}$ on the electrode surface [13]. For stepped surfaces, the orientation of water can be different on the steps and on the terrace. Moreover, it has been described that the local reorientation of water molecules on step sites triggers the reorientation of a significant fraction of the water adlayer on the whole surface [43]. Thus, the pme of the terrace and the steps changes with the step density of the surface. To be more precise, the pme and then the $\mathrm{E}_{\text {inhibition }}$ is shifted to more positive potentials with the step density in acid media. Unlike acidic solutions, in alkaline media it has been shown that the pme moves in the opposite direction, it is, the pme is shifted to more negative potentials with the step density [44]. Thus, a decrease in the $\mathrm{E}_{\text {inhi- }}$ 


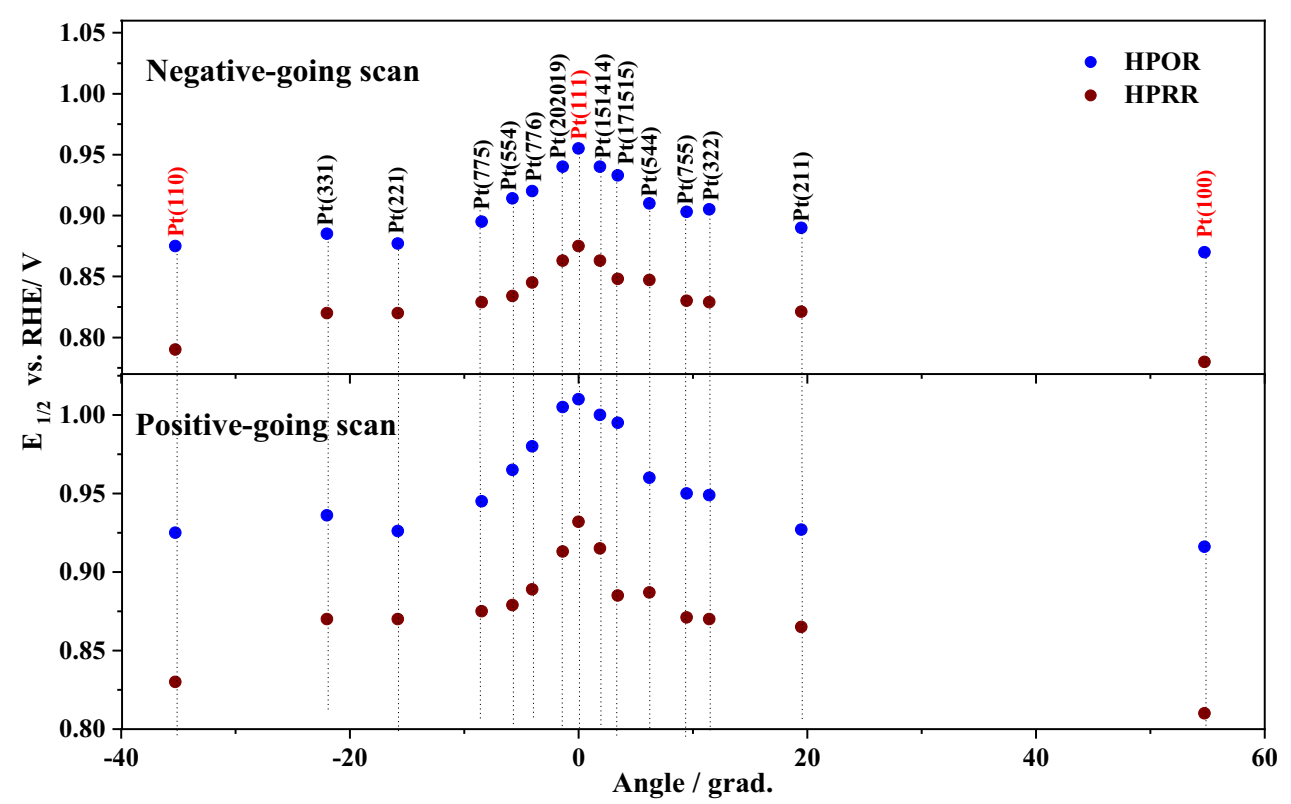

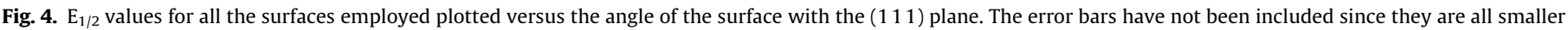
than the data point symbol and imperceptible within the employed scale range.

bition by increasing the step density would be expected. However, as explained above, the pme at $\mathrm{pH}=13(\sim 0.80$ vs RHE for Pt (111)) would lie in the region of adsorbed $\mathrm{OH}$ [44]. This species has a buffering effect, which alters this correspondence when $E_{\text {inhibition }}$ is close to the potential for the adsorption of $\mathrm{OH}$, and is responsible for the constant value of $E_{\text {inhibition }}$ with the step density. Thus, at this $\mathrm{pH}, E_{\text {inhibition }}$ is not governed by the pme but by adsorbed $\mathrm{OH}$. This process lies in the same potential region for all the stepped surfaces in the same set of surfaces. This effect can be observed for the $\mathrm{Pt}(\mathrm{S})[(n-1)(111) \times(110)]$ surfaces in Fig. 3A. In this case, $E_{\text {inhibition }}$ coincides with the onset potential for the adsorption of $\mathrm{OH}(0.64 \mathrm{~V})$, as shown in the profiles from Fig. 2A, and does not change with the step density. Additionally, a small increase in the reduction current is observed at ca. $0.28 \mathrm{~V}$, which coincides with the position of the peaks corresponding to the step. The increase is more evident as the step density increases, indicating that the steps are also taking part in the HPRR, but with lower activity, and deactivate at potentials lower than the peak. In a previous report, it was found that the pme of the step sites lies exactly in the same potential region that the voltammetric peak for the steps and then a reorganization of the water molecules, and, thus, a reactivation of the HPRR is expected in this region [44].

Unlike the surfaces with (110) steps, a shift in the position of $E_{\text {inhibition }}$ with the step density is shown in the surfaces with (111) terraces and (100) steps (Fig. 3B). In this case, the reactivation of the HPRR is expected at the position of the peak associated with the steps, that is, at ca. $0.4 \mathrm{~V}$. Moreover, the potential for this peak moves to more negative values as the step density increase. Therefore, the change in $E_{\text {inhibition }}$ with the step density for the Pt $(S)[n(111) \times(100)]$ surfaces is the results of two different processes, the inhibition on the terraces at $\mathrm{E}<0.64 \mathrm{~V}$ and the reactivation of the HPRR at potentials positive to the step. At potentials negative to this peak the reaction is inhibited again, resulting in a value for $E_{\text {inhibition }}$ that diminishes with the step density. In the case of the $\mathrm{Pt}(311)$, with a short terrace (only 2 atoms in the terrace), the contribution of the steps to the reactivation of the HPRR is so high that the limiting current is not well-defined.

To further investigate the inhibition at low potentials and the existence/stability of possible intermediates formed during this pathway, different rotation rates were employed using $\operatorname{Pt}(211)$ and $\operatorname{Pt}(221)$ surfaces. These surfaces have 2 atom wide terraces and monoatomic (100) and (110) steps, respectively. Fig. 5 shows that the inhibition in the current density at low potentials is dependent on the rotation rate and that this decrease in the current becomes higher as the rotation rate increases. However, this effect is lower on $\operatorname{Pt}(221)$ than on $\operatorname{Pt}(211)$, as can be seen in Fig. $6 \mathrm{C}$ where the normalized difference between the limiting current and the current at $0.1 \mathrm{~V}$ is plotted vs. the square root of the rotation rate. For the $\mathrm{Pt}(221)$ surface, the inhibition is small and almost independent of the rotation rate. On the other hand, a linear increase with the square root of the rotation rate is observed for the $\operatorname{Pt}(211)$ electrode. This linear dependence with the rotation rate implies that an intermediate is being desorbed from the surface. Thus, the inhibition of the HPRR is not due to a $\mathrm{H}_{\mathrm{ads}}$ on Pt, which may inhibit the interaction of $\mathrm{H}_{2} \mathrm{O}_{2}$ with the Pt surface, but due to an adsorbed HPRR intermediate. This intermediate is weakly adsorbed so that it can desorb easily from the surface, and the high rotation removes the intermediate species from the interphase so that it cannot readsorb and further oxidize. Furthermore, this intermediate is more strongly adsorbed on $\operatorname{Pt}(221)$ than $\mathrm{Pt}(211)$, which suggests that this intermediate has more affinity with (110) steps than with (100) steps.

\subsection{Mechanistic insights for the ORR before and after the formation of $\mathrm{H}_{2} \mathrm{O}_{2}$}

Since hydrogen peroxide is a possible intermediate of the ORR, the comparison between ORR and HPRR is of paramount importance in order to get a deeper insight into the reaction mechanism. Fig. 6 shows the voltammetric profiles for the HPRR and ORR on Pt (111) and stepped surfaces with 111 terraces. For comparison, currents have been normalized using the value of the limiting current density for the ORR and HPRR, so that the effect of the different number of electrons transferred in the reactions are taken into account.

This figure clearly illustrates the differences and similarities between both reactions. Two regions can be distinguished. At low overpotentials, the onset for both reactions is very close, although the half-wave potentials shown in Fig. 4 for the HPRR are higher than those for the ORR reported in [7]. Additionally, 

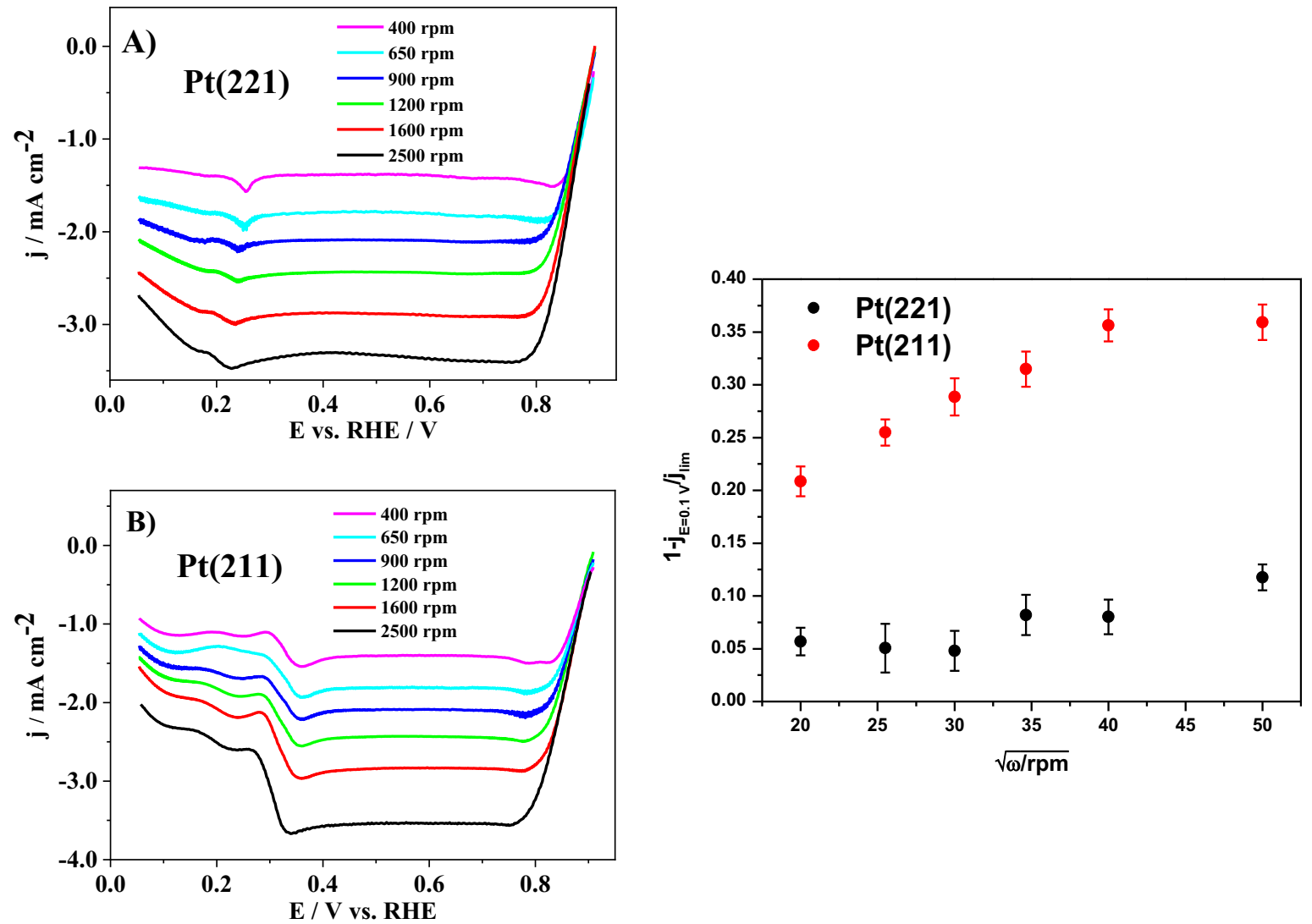

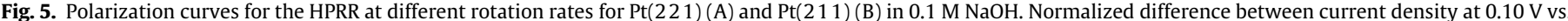

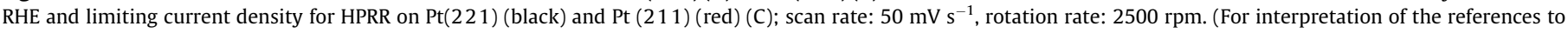
colour in this figure legend, the reader is referred to the web version of this article.)
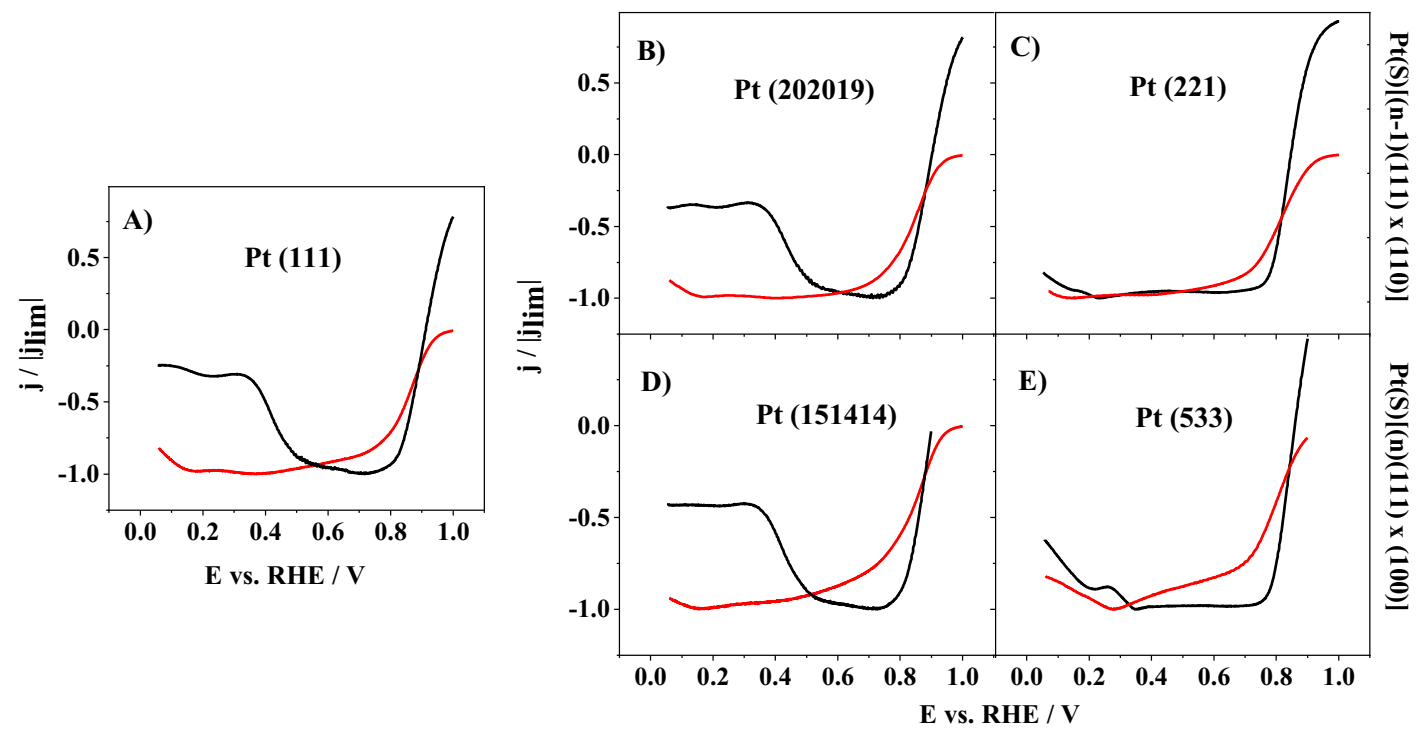

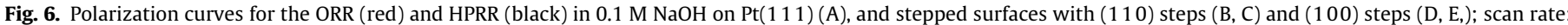

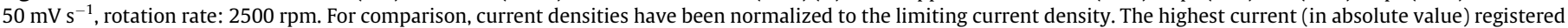

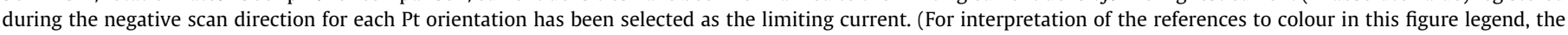
reader is referred to the web version of this article.)

the rising part of the curve for the ORR is less steep than for HPRR, implying that the ORR reaction has lower activity in this potential region. According to the different proposed mechanisms, $\mathrm{OOH}, \mathrm{OH}$, and $\mathrm{O}$ are the adsorbed intermediates proposed for the ORR $[8,45]$, which essentially are the same as those proposed for the HPRR. Moreover, it has been observed that the adsorption energies of those intermediates are strongly correlated so that they follow scaling relationships. For this reason, the lower activity of the 
ORR observed here has to be related to the first step in the reaction, that involving the first electron transfer to form the adsorbed $\mathrm{OOH}$ is $[9,10]$ or the superoxide anion radical $\left(\mathrm{O}_{2}^{-}\right)$in alkaline media [11-13], since the HPRR is faster than the ORR.

On the other hand, the currents in the region where the inhibition takes place show significant differences (Fig. 6). It should be highlighted that the normalization by the limiting current implies that if $\mathrm{H}_{2} \mathrm{O}_{2}$ reduction is completely inhibited the value for $\mathrm{j} /\left|\mathrm{j}_{\text {lim }}\right|$ should be zero for the HPRR. In the case of the ORR, if $\mathrm{H}_{2} \mathrm{O}_{2}$ is an intermediate and its reduction is completely inhibited the normalized current should be -0.5 . Taking this fact into consideration, it can be observed that for surfaces with wide terraces, the inhibition is much lower for ORR than for HPRR. However, the inhibition for the ORR increases as the step density increases, which is the opposite behavior of the inhibition of the HPRR. This different trend can be observed in Fig. 7, in which in the normalized difference between the current at $\mathrm{E}=0.1 \mathrm{~V}$ and the limiting diffusion current for ORR and HPRR on all the surfaces employed in this work has been plotted vs. the step density. To account for the different numbers of electrons exchanged in the processes, the normalized values for the ORR have been multiplied by 2 . If the inhibition for the ORR is due to the inhibition of the HPRR, two electrons would have been exchanged in the ORR before the formation of hydrogen peroxide and the normalized difference of the currents would have been 0.5 . The multiplication by 2 of the inhibition factor for the ORR allows a better comparison with the HPRR. As can be seen, for surfaces with wide terraces, the inhibition for the ORR is much lower than in the case of the HPRR. However, as the step density increases the inhibition for the ORR increases whereas the inhibition for the HPRR decreases. For surfaces with a low number of atoms in the terrace ( $\mathrm{n}<7$ for surfaces with (110) steps and $\mathrm{n}<4$ form surfaces with (100) steps), the inhibition for the ORR is even higher than for HPRR. These differences seem to indicate that, although $\mathrm{H}_{2} \mathrm{O}_{2}$ may be involved in the ORR as an intermediate in alkaline electrolytes, the mechanism is not taking place via the total conversion of $\mathrm{O}_{2}$ to $\mathrm{H}_{2} \mathrm{O}_{2}$ but there should be a double mechanism with a bifurcation before $\mathrm{H}_{2} \mathrm{O}_{2}$ is formed. For the surfaces

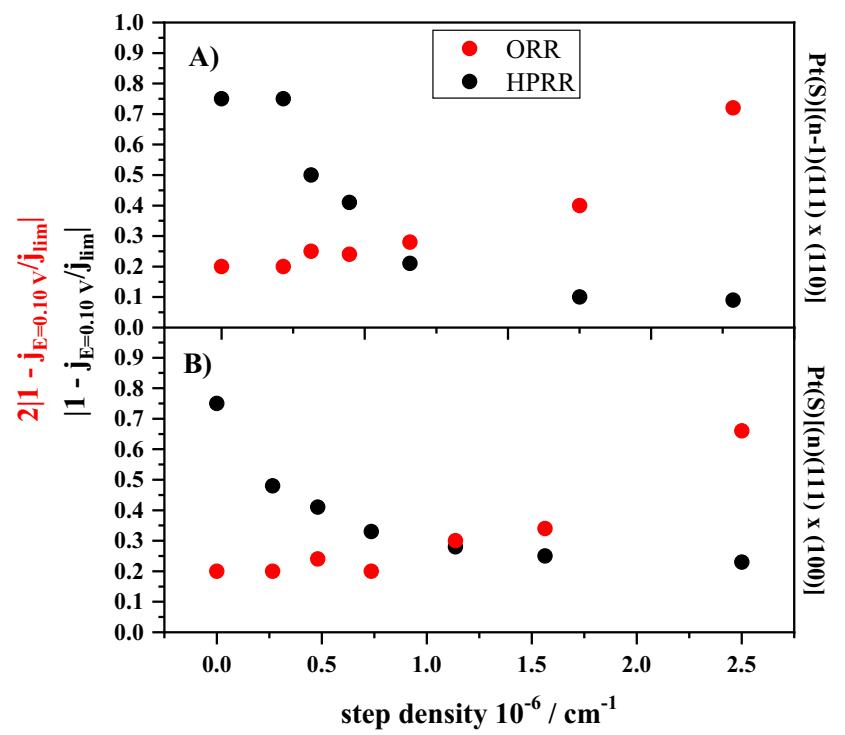

Fig. 7. Difference between current density at $0.10 \mathrm{~V}$ vs. RHE and limiting current density for HPRR (black) and ORR (red), in this case the value is multiplied by 2 for $\mathrm{Pt}(\mathrm{S})[(\mathrm{n}-1)(111) \times(110)](\mathrm{A}) \mathrm{Pt}(\mathrm{S})[(\mathrm{n})(111) \times(100)](\mathrm{B})$ surfaces in $0.1 \mathrm{M} \mathrm{NaOH}$. The error bars have not been included since they are all smaller than the data point symbol and imperceptible within the employed scale range. The highest current (in absolute value) registered during the negative scan direction for each Pt orientation has been selected as the limiting current. (For interpretation of the references to colour in this figure legend, the reader is referred to the web version of this article.) with wide terraces, this bifurcation point before the $\mathrm{H}_{2} \mathrm{O}_{2}$ formation leads to a low deactivation of the ORR at $0.10 \mathrm{~V}$. For short terrace surfaces, the deactivation is important, almost equivalent to 2 electrons. The latter suggests that the ORR is being inhibited before the exchange of the second electron.

Given the results, three different possibilities arise:

1. The decrease in current density at low potentials occurs because the ORR is inhibited because not all the $\mathrm{O}_{2}$ molecules can react.

2. The ORR ends right after the formation of an intermediate different from $\mathrm{H}_{2} \mathrm{O}_{2}$, in a one-electron transfer process, and that this intermediate desorbs at low potentials. In acid media, the possibility of a bifurcation mechanism and the formation of $\mathrm{OOH}$ as the intermediate before the formation of $\mathrm{H}_{2} \mathrm{O}_{2}$ has already been proposed [1,9,10,46-48]. However, in the present scenario $(\mathrm{pH}=13)$, the superoxide anion, $\mathrm{O}_{2}^{-}$, is probably the intermediate responsible for these changes, previously identified by spectroscopic studies in alkaline media [11].

3. The ORR reaction ends right after 2 electrons are transferred and then the intermediate desorbs.

From the three hypotheses, the last one implies the formation of $\mathrm{H}_{2} \mathrm{O}_{2}$, which is the only intermediate that could be formed in a 2electron transfer process. It should be beard in mind that, at this $\mathrm{pH}$ value, $\mathrm{HO}_{2}^{-}$is in the main species in solution. Also, at this $\mathrm{pH}$ value, the surface charge of the pristine Pt single crystal surfaces should be negative [49], implying that the interaction of $\mathrm{HO}_{2}^{-}$with the electrode surface is unfavorable. Thus, if $\mathrm{H}_{2} \mathrm{O}_{2} / \mathrm{HO}_{2}^{-}$are formed as intermediate in the ORR, the interaction with the surface would be weak and the inhibition behavior would follow the same as that observed for HPRR, which is not the case. Thus, the formation of $\mathrm{H}_{2} \mathrm{O}_{2}$ as an intermediate is not a major route in the ORR at these potentials and, hypotheses 1 and 2 are the only reasonable possibilities that can explain the different current densities in the inhibition region for the ORR curves. Probably, the formation of $\mathrm{O}_{2}^{--}$, whose interaction with the surface will also not be favorable due to the negative charge of the surface, would be part of the main route for the inhibition. Anyhow, minor participation of other routes cannot be discarded.

\section{Conclusions}

The results presented here clearly demonstrate the complexity of the HPRR and ORR. The onset potential for both reactions appears to be dominated by the presence and lability of adsorbed $\mathrm{OH}$. Thus, the highest rates at high potentials are obtained for the $\mathrm{Pt}(111)$ electrode, because adsorbed $\mathrm{OH}$ is more labile on this surface at ca. $0.9 \mathrm{~V}$. The lower activity for the ORR in this region (when compared to the HPRR) has been explained by the slow rate of the first electron transfer in the ORR. On the other hand, the inhibition of the reaction at low potentials for the HPRR on different Pt stepped surfaces with (111) terraces in $0.1 \mathrm{M} \mathrm{NaOH}$ point out that there is a relationship between the value of $E_{\text {inhibition }}$ of this reaction and the pme and the presence of adsorbed $\mathrm{OH}$. For surfaces with (110) monoatomic steps, the $E_{\text {inhibition }}$ does not change with the step density and coincides with the desorption of $\mathrm{OH}$. However, a shift with the step density is shown for $E_{\text {inhibition }}$ on surfaces with (100) steps, due to the reactivation of the HPRR at the (100) steps. Furthermore, the calculation of $E_{1 / 2}$ from the polarization curves for all the employed surfaces revealed that Pt (111) is the most active surface for the HPRR, and its activity progressively decreases when (110) and/or (100) steps are introduced into the (111) surface. The latter is a clear indication that the steps are less active than the terrace sites, in analogy to the behavior previously 
obtained for ORR in the same electrolyte. Additionally, experiments using different rotation rates demonstrated that the inhibition of the HPRR is not due to a $\mathrm{H}_{\mathrm{ads}}$ on Pt, which may inhibit the interaction of $\mathrm{H}_{2} \mathrm{O}_{2}$ with the Pt surface, but due to an adsorbed HPRR intermediate, which is more strongly adsorbed on (110) than on (100) steps. Finally, a close comparison of the HPRR and ORR clearly illustrated the important differences for both reactions and that these differences are dependent on the step density. More precisely, for wide terrace surfaces, the inhibition for the ORR is much lower than in the case of the HPRR. However, as the step density increases the inhibition for the ORR increases whereas the inhibition for the HPRR decreases. Two hypotheses have been considered to explain these differences: the formation of an intermediate, different to $\mathrm{H}_{2} \mathrm{O}_{2}$, in a one-electron-transfer process and/ or an impeded $\mathrm{O}_{2}$ interaction with the Pt surface.

\section{Declaration of Competing Interest}

The authors declare that they have no known competing financial interests or personal relationships that could have appeared to influence the work reported in this paper.

\section{Acknowledgments.}

Financial support from Ministerio de Ciencia e Innovación (Project PID2019-105653 GB-100) and Generalitat Valenciana (Project PROMETEO/2020/063) is acknowledged.

\section{Appendix A. Supplementary data}

Supplementary data to this article can be found online at https://doi.org/10.1016/j.jcat.2021.04.018.

\section{References}

[1] A.M. Gómez-Marín, R. Rizo, J.M. Feliu, Oxygen reduction reaction at Pt single crystals: a critical overview, Catal. Sci. Technol. 4 (2014) 1685-1698.

[2] H.A. Gasteiger, N.M. Marković, Just a dream-or future reality?, Science 324 (2009) 48-49.

[3] S. Guo, S. Zhang, S. Sun, Tuning nanoparticle catalysis for the oxygen reduction reaction, Angew. Chem. - Int. Ed. 52 (2013) 8526-8544.

[4] R.R. Adzic, Recent advances in the kinetics of oxygen reduction, in: J. Lipkowski, P.N. Ross (Eds.), Electrocatalysis, Wiley-VCH, New York, 1998, pp. $197-275$.

[5] J.A. Keith, T. Jacob, Theoretical studies of potential-dependent and competing mechanisms of the electrocatalytic oxygen reduction reaction on Pt (111), Angew. Chem. Int. Ed. 49 (2010) 9521-9525.

[6] V. Tripković, E. Skúlason, S. Siahrostami, J.K. Nørskov, J. Rossmeisl, The oxygen reduction reaction mechanism on Pt (1 111 ) from density functional theory calculations, Electrochim. Acta 55 (2010) 7975-7981.

[7] R. Rizo, E. Herrero, J.M. Feliu, Oxygen reduction reaction on stepped platinum surfaces in alkaline media, Phys. Chem. Chem. Phys. 15 (2013) 15416-15425.

[8] J.K. Nørskov, J. Rossmeisl, A. Logadottir, L. Lindqvist, J.R. Kitchin, T. Bligaard, H. Jónsson, Origin of the overpotential for oxygen reduction at a fuel-cell cathode, J. Phys. Chem. B 108 (2004) 17886-17892.

[9] A. Gómez-Marín, J. Feliu, T. Edson, Reaction mechanism for oxygen reduction on platinum: existence of a fast initial chemical step and a soluble species different from H2O2, ACS Catal. 8 (2018) 7931-7943.

[10] A.M. Gomez-Marin, J.M. Feliu, New Insights into the Oxygen Reduction Reaction Mechanism on Pt(111): A Detailed Electrochemical Study, ChemSusChem 6 (2013) 1091-1100.

[11] M. Shao, P. Liu, R.R. Adzic, Superoxide anion is the intermediate in the oxygen reduction reaction on platinum electrodes, J. Am. Chem. Soc. 128 (2006) 74087409.

[12] V. Briega-Martos, A. Ferre-Vilaplana, E. Herrero, J.M. Feliu, Why the activity of the hydrogen oxidation reaction on platinum decreases as $\mathrm{pH}$ increases, Electrochim. Acta 354 (2020) 136620-136632.

[13] V. Briega-Martos, E. Herrero, J.M. Feliu, Hydrogen peroxide and oxygen reduction studies on $\mathrm{Pt}$ stepped surfaces: Surface charge effects and mechanistic consequences, Electrochim. Acta 334 (2020) 135452.

[14] V. Briega-Martos, E. Herrero, J.M. Feliu, Pt(hkl) surface charge and reactivity, Curr. Opin. Electrochem. 17 (2019) 97-105.

[15] N.M. Marković, R.R. Adžić, B.D. Cahan, E.B. Yeager, Structural effects in electrocatalysis: oxygen reduction on platinum low index single-crystal surfaces in perchloric acid solutions, J. Electroanal. Chem. 377 (1994) 249-259.
[16] M.D. Maciá, J.M. Campiña, E. Herrero, J.M. Feliu, On the kinetics of oxygen reduction on platinum stepped surfaces in acidic media, J. Electroanal. Chem. 564 (2004) 141-150.

[17] A. Kuzume, E. Herrero, J.M. Feliu, Oxygen reduction on stepped platinum surfaces in acidic media, J. Electroanal. Chem. 599 (2007) 333-343.

[18] C. Korzeniewski, V. Climent, J. Feliu, Electrochemistry at Platinum Single Crystal Electrodes, in: A.J. Bard, C.G. Zoski (Eds.), Electroanal. Chem. A Ser. Adv., CRC Press, Roca Raton, 2011, pp. 75-170.

[19] J.M. Feliu, A. Rodes, J.M. Orts, J. Clavilier, The problem of surface order of Pt single crystals in electrochemistry, Pol. J. Chem. 68 (1994) 1575-1596.

[20] E. Herrero, J.M. Orts, A. Aldaz, J.M. Feliu, Scanning tunneling microscopy and electrochemical study of the surface structure of $\mathrm{Pt}(10,10,9)$ and $\mathrm{Pt}(11,10,10)$ electrodes prepared under different cooling conditions, Surf. Sci. 440 (1999) $259-270$.

[21] N. García-Aráez, V. Climent, E. Herrero, J.M. Feliu, On the electrochemical behavior of the Pt(1 0 0) vicinal surfaces in bromide solutions, Surf. Sci. 560 (2004) 269-284

[22] G.A. Attard, A. Brew, Cyclic voltammetry and oxygen reduction activity of the Pt $\left\{\begin{array}{lll}1 & 1 & 0\end{array}\right\}-(1 \times 1)$ surface, J. Electroanal. Chem. 747 (2015) 123-129.

[23] E. Morallón, J. Vázquez, R. Duo, A. Aldaz, Adsorption of CO on a Pt (110) surface in a carbonate solution: Voltammetric investigation of the possible $(1 \times 2) \rightarrow$ $(1 \times 1)$ structural transformation, Surf. Sci. 278 (1992) 33-40.

[24] L.A. Kibler, A. Cuesta, M. Kleinert, D.M. Kolb, In-situ STM characterisation of the surface morphology of platinum single crystal electrodes as a function of their preparation, J. Electroanal. Chem. 484 (2000) 73-82.

[25] M.J.T.C. Van Der Niet, N. Garcia-Araez, J. Hernández, J.M. Feliu, M.T.M. Koper Water dissociation on well-defined platinum surfaces: The electrochemical perspective, Catal. Today 202 (2013) 105-113.

[26] A.S. Bondarenko, I.E.L. Stephens, H.A. Hansen, F.J. Perez-Alonso, V. Tripkovic, T. P. Johansson, J. Rossmeisl, J.K. Norskov, I. Chorkendorff, The Pt(111)/Electrolyte Interface under Oxygen Reduction Reaction Conditions: An Electrochemical Impedance Spectroscopy Study, Langmuir 27 (2011) 2058-2066.

[27] N.M. Markovića, S.T. Sarraf, H.A. Gasteiger, P.N. Ross, Hydrogen electrochemistry on platinum low-index single-crystal surfaces in alkaline solution, J. Chem. Soc. Faraday Trans. 92 (1996) 3719-3725.

[28] A. Björling, E. Herrero, J.M. Feliu, Electrochemical oxidation of Pt(1 111 ) vicinal surfaces: Effects of surface structure and specific anion adsorption, J. Phys. Chem. C 115 (2011) 15509-15515.

[29] A. Björling, J.M. Feliu, Electrochemical surface reordering of $\operatorname{Pt}\left(\begin{array}{lll}1 & 1 & 1\end{array}\right)$ : A quantification of the place-exchange process, J. Electroanal. Chem. 662 (2011) $17-24$.

[30] R.M. Arán-Ais, M.C. Figueiredo, F.J. Vidal-Iglesias, V. Climent, E. Herrero, J.M. Feliu, On the behavior of the Pt $\left(\begin{array}{lll}1 & 0 & 0\end{array}\right)$ and vicinal surfaces in alkaline media, Electrochim. Acta 58 (2011) 184-192.

[31] I. Katsounaros, K.J.J. Mayrhofer, The influence of non-covalent interactions on the hydrogen peroxide electrochemistry on platinum in alkaline electrolytes, Chem. Commun. 48 (2012) 6660-6662.

[32] F.J. Vidal-Iglesias, J. Solla-Gullón, V. Montiel, A. Aldaz, Errors in the use of the Koutecky-Levich plots, Electrochem. Commun. 15 (2012) 42-45.

[33] P. Sebastián, R. Martínez-Hincapié, V. Climent, J.M. Feliu, Study of the Pt(111)| electrolyte interface in the region close to neutral $\mathrm{pH}$ solutions by the laser induced temperature jump technique, Electrochim. Acta 228 (2017) 667-676.

[34] J. Huang, A. Malek, J. Zhang, M.H. Eikerling, Non-monotonic Surface Charging Behavior of Platinum: A Paradigm Change, J. Phys. Chem. C 120 (2016) 1358713595.

[35] R. Smoluchowski, Anisotropy of the electronic work function of metals, Phys. Rev. 60 (1941) 661-674.

[36] J. Lecoeur, J.P. Bellier, C. Koehler, Dipole effects of (100) monoatomic steps of gold $\mathrm{n}(111) \mathrm{x}(100)$ vicinal faces in contact with aqueous solutions and under ultrahigh vacuum, J. Electroanal. Chem. 375 (1994) 117-122.

[37] G.L. Beltramo, H. Ibach, M. Giesen, A novel approach to measure the step line tension and the step dipole moment on vicinal $\mathrm{Au}(00 \mathrm{0})$ 1) electrodes, Surf. Sci. 601 (2007) 1876-1885.

[38] V. Grozovski, V. Climent, E. Herrero, J.M. Feliu, Intrinsic activity and poisoning rate for $\mathrm{HCOOH}$ oxidation at $\mathrm{Pt}(100)$ and vicinal surfaces containing monoatomic (111) steps, ChemPhysChem 10 (2009) 1922-1926.

[39] V. Grozovski, V. Climent, E. Herrero, J.M. Feliu, The role of the surface structure in the oxidation mechanism of methanol, J. Electroanal. Chem. 662 (2011) 4351.

[40] E. Sitta, A.M. Gomez-Marin, A. Aldaz, J.M. Feliu, Electrocatalysis of H2O2 reduction/oxidation at model platinum surfaces, Electrochem. Commun. 33 (2013) 39-42.

[41] N. Markovic, H. Gasteiger, P.N. Ross, Kinetics of oxygen reduction on Pt(hkl) electrodes: Implications for the crystallite size effect with supported Pt electrocatalysts, J. Electrochem. Soc. 144 (1997) 1591-1597.

[42] N.M. Markovic, H.A. Gasteiger, P.N. Ross Jr, Oxygen reduction on platinum lowindex single-crystal surfaces in sulfuric acid solution: rotating ring-Pt (hkl) disk studies, J. Phys. Chem. 99 (1995) 3411-3415.

[43] N. Garcia-Araez, V. Climent, J. Feliu, Potential-dependent water orientation on Pt (111), Pt (100), and Pt (110), as inferred from laser-pulsed experiments. Electrostatic and chemical effects, J. Phys. Chem. C 113 (2009) 9290-9304.

[44] F.J. Sarabia, P. Sebastián, V. Climent, J.M. Feliu, New insights into the Pt (hkl)alkaline solution interphases from the laser induced temperature jump method, J. Electroanal. Chem. 872 (2020) 114068-114078.

[45] M.T.M. Koper, Thermodynamic theory of multi-electron transfer reactions: Implications for electrocatalysis, J. Electroanal. Chem. 660 (2011) 254-260. 
[46] V. Briega-Martos, E. Herrero, J.M. Feliu, Effect of pH and water structure on the oxygen reduction reaction on platinum electrodes, Electrochim. Acta 241 (2017) 497-509.

[47] J.-C. Dong, X.-G. Zhang, V. Briega-Martos, X. Jin, J. Yang, S. Chen, Z.-L. Yang, D.Y. Wu, J.M. Feliu, C.T. Williams, In situ Raman spectroscopic evidence for oxygen reduction reaction intermediates at platinum single-crystal surfaces, Nat. Energy 4 (2019) 60-67.
[48] S. Nayak, I.J. McPherson, K.A. Vincent, Adsorbed intermediates in oxygen reduction on platinum nanoparticles observed by in situ IR spectroscopy, Angew. Chem. 130 (2018) 13037-13040.

[49] R. Rizo, E. Sitta, E. Herrero, V. Climent, J.M. Feliu, Towards the understanding of the interfacial pH scale at Pt $\left(\begin{array}{llll}1 & 1 & 1\end{array}\right)$ electrodes, Electrochim. Acta 162 (2015) 138-145. 